\title{
Adhesion G Protein-Coupled Receptor L3
}

National Cancer Institute

\section{Source}

National Cancer Institute. Adhesion G Protein-Coupled Receptor L3. NCI Thesaurus. Code C150275.

Adhesion G protein-coupled receptor L3 (1447 aa, 162 kDa) is encoded by the human ADGRL3 gene. This protein plays a role in G protein-coupled receptor signaling, neuronal migration and cell-cell adhesion. 